\title{
NULL SUBJECT PHENOMENA IN JAPANESE: INCORPORATION, NULL EXPLETIVES, AND TOPIC-AGREEMENT
}

\author{
Atsuro Tsubomoto \\ Hyogo University of Education
}

\begin{abstract}
The purpose of this paper is to consider the non-overt NP in the canonical subject position and the Topic node of sentences which contain some epistemic modal-like elements, i.e. no-da, yoo-da, hazu-da, etc. It is claimed that these elements are synthetic forms derived by Incorporation (Baker 1985, 1988), by assuming $d a$ either as a (unaccusative) verb or as the Present Tense marker. Besides the usual Topic, what I shall term Situational ToPIC, Topic $\mathrm{s}_{\mathrm{s}}$, is proposed. This Topic strongly depends on discourse and reflects the speaker's Modality. In this sense, Topic $\mathrm{s}_{\mathrm{s}}$ can be characterized as TOPIC of MoDALITY. The co-occurence properties of epistemic modal-like elements with Topic $\mathrm{s}_{\mathrm{S}}$, either overt or zero, and with sometimes overt epistemic adverbs are explained in terms of Spec-head agreement. It is claimed that Japanese is a Topic (of Modality)-agreement language, although there is no 'strong agreement'.*
\end{abstract}

0. InTRODUCTION. In recent years, contrastive linguistics has been recast in terms of GB theory or the principles-and-parameters model (Chomsky 1981, 1982, 1986a, 1986b). A phenomenon which has enjoyed a lot of attention within the model is the so-called pro-drop or null subject parameter. To my knowledge, the null subject (NS) phenomena in Japanese have not been widely researched within the PP framework (but, see Saito 1985). Four points (at least) ${ }^{1}$ concerning NS phenomena have been claimed in the literature, and these should be taken into consideration when we talk about the NS construction: (a) the pronominal status of Infl (Rizzi 1982, Hyams 1986), (b) the potential dual status, referential

* I am indebted to Ken-ichi Mihara and Hideo Ohashi for helpful comments and discussions. I am also grateful to two anonymous referees for critical notes on the previous version of the analysis presented here. My thanks go to John Chick for correcting stylistic errors. All the shortcomings that may remain are of course my own.

1 Also extensively investigated in the last few years in the context of null subject constructions is the particular form of subject verb agreement operating in such languages as Welsh, Irish, and Breton. (McCloskey and Hale 1984, Stump 1984, Sadler 1988, among others.)

English Linguistics 6 (1989) 130-149 -130-

(C) 1989 by the English Linguistic Society of Japan 
or expletive, of the null subject (Chomsky 1982), (c) besides the Pro-drop Parameter, the importance of a typological parameter allowing, or not allowing a Zero Topic (Huang 1984), and (d) following Rizzi 1986, formal licensing and recovery of pro should be separated.

The purpose of this paper is to discuss syntactic and semantic properties of sentences like 1 , which contain italicized epistemic auxiliary-like expressions, with regard to the above points.

(1) a. Chomusukii-ga Nihon-ni kuru yoo-da.

Chomsky-nom Japan-to come seem

'It seems that Chomsky will come to Japan.'

b. Ame-ga huru soo-da.

rain-nom fall it-is-said

'It is said that it will rain.'

c. Hanako-ni nanika kanasii koto-ga at-ta no-da. -to something sad fact-nom exist-past $\mathrm{N}$-be

'It is that something sad happened to Hanako.'

d. Kimi-ga sikkari eigo-o benkyoo suru koto-da. yoo-nom hard English-acc study do fact be

(Lit.) 'It should be the case that you study English hard.'

I will argue that examples like 1 can be characterized as what I shall henceforth call $d a$-constructions. There are several other types of $d a$ constructions, as exemplified in 2 and 3 :

(2) Daitooryoo-wa Reagan da.

President-top be

'The President is Reagan.'

(3) Mary-wa tensai da.

-top genius be

'Mary is a genius.'

A full-fledged survey of $d a$ 'be' is not my concern here, but a different type of $d a$-construction will be introduced which is closely related with 'Situational Topic' referring to the states or environment (including the preceding context) under which the utterance is made. It will be argued that sentences like 1 mirror the general properties of this type of $d a$-construction.

1. The Situational Topic Construction. There are some discussions and disputes with regard to whether in Japanese a sentence initialTopic can be base-generated in that position or can be moved to that position. (Kuno 1973, Saito 1985, Kuroda 1965, 1987 among others.) Ac- 
cording to Kuno, Topic in Japanese is licensed by some sort of ABOUTNESS RELATION holding between Topic and the rest of the sentence and that Topic does not need to bind any argument position, as sentences like 4 show. Kuno further notes that the Topic construction does allow overt resumptive pronouns as in 5 (cf. Saito 1985):

(4) a. Sakana-wa [s tai-ga oisii]

fish-top red snapper-nom tasty 'Speaking of fish, red snapper is tasty.'

b. Hana-wa [s sakura-ga ii] flower-top cherry blossams-nom good 'Speaking of flowers, cherry blossams are the best.'

( 5 ) a. ?Sono hito ${ }_{i}$-wa [s John-ga kare ${ }_{i}$-no imooto-o yoku that person-top -nom he-gen sister-acc well sitte iru rasii] know seem 'Speaking of that person, it seems that John know his sister very well.'

b. ?Sono boosi $\mathrm{i}_{\mathrm{i}}$-wa [s $_{\mathrm{S}}$ John-ga $\left[_{\mathrm{NP}} \mathrm{e}_{\mathrm{j}}\right.$ sore $_{\mathrm{i}}-\mathrm{o}$ kabutte ita that hat-top -nom it-acc wearing was hito $\mathrm{j}_{\mathrm{j}}$ ]-o yoku sitte iru rasii] person-acc well know seem 'Speaking of that hat, it seems that John knows the person who was wearing it very well.'

(Saito 1985: 312)

Saito 1985: 317 states that although an NP in an adjoined position must bind a variable in order to avoid 'vacuous quantification', Topic in Japanese, which is assumed to be adjoined to $\mathrm{S}$ by Kuno 1973, need not bind a variable when it can be licensed by the ABOUTNESS RELATION.

Saito 1985, following Perlmutter 1972, proposes the following structure when a Topic binds a gap in the sentence. In 6, Topic is base-generated, and $e_{i}$ can be a null pronoun, which explains the lack of the island effects in $5 \mathrm{~b}$ :

(6) $\left[\mathrm{s}\right.$ Topic $\left._{\mathrm{i}}\left[\mathrm{s} \ldots \mathrm{e}_{\mathrm{i}} \ldots\right]\right]$

There have traditionally been many suggestions and disputes with regard to whether $d a$ is categorized either as a kind of modal auxiliary (thus under the Infl node in GB theory) or as a verb. Some peculiar restriction on the occurrence of the canonical subject of $d a$-constructions should be noted, assuming the Extended Projection Principle (Chomsky 1982: 10) that clauses have subjects. ${ }^{2}$ The sentences in 7 show that null pronouns can also appear overtly in the subject position (here the genitive form) in 
confirmity with 6 (as in example 5a):

(7) a. ?Daitooryoo ${ }^{-}$-wa $\left(\mathrm{so}_{\mathrm{i}}\right.$-no namae-ga) Reagan da. President-top it-gen name-nom be

(Lit.) 'Speaking of the President, (his name) is Reagan.'

b. ? $\mathrm{John}_{\mathrm{i}}$-wa (so $\mathrm{i}_{\mathrm{i}}$-no sigoto-ga) sensei da

-top (it-gen occupation-nom) teacher be

(Lit.) 'Speaking of John, (his occupation) is a teacher.'

In simple sentences, $g a$-phrases in $d a$-constructions imply so-called 'exhaustive listing' interpretation (Kuno 1973) or 'focus' reading. (Mikami 1953) The examples in 8, however, show that $g a$-phrases can appear in embedded sentences without necessarily implying such a marked interpretation.

( 8 ) a. Minna-ga [daitooryo-ga Reagan da] to yuu koto-o everyone-nom President-nom be COMP fact-acc sitte iru.

know

'Everyone knows that the President is Reagan.'

b. Watasi-wa [John-ga sensei da] to yuu koto-ga

I -top -nom teacher be COMP fact-nom

sinji rarenai.

believe cannot

'I cannot believe that John is a teacher.'

The above facts lead to the idea that the canonical subject position of $d a$-constructions is an argument position where an overt NP can appear. However, we have good reason to believe that some types of $d a$-construction do not allow any argument in the [NP, S] position.

Consider example 9B in response to 9A's remark:

(9) A: Daidokoro-ga nandaka urusai ne.

kitchen-nom rather noisy tag $\mathrm{Q}$

'It's rather noisy in the kitchen, isn't it?'

B: Are-wa nezumi da.

that-top mouse be

(Lit.) 'That is a mouse.'

Are is ambiguous in that it can refer to a vague object, usually the circumstances under which the utterance is made, as well as a definite pronoun (Mikami 1960: 84). The first case can be compared with so-called

2 We assume that Japanese is a configurational language with a VP node. See Hoji 1985, Kuroda 1983, Saito 1983, 1985, Whitman 1986 for relevant discussion. 
'situation it' in English (cf. 10), while the latter case can be equivalent to the real pronoun that in English, which is anaphorically related with a real object, and hence can be paraphrased as ano buttai 'that object'. This usage of, say, the Situational Topic Construction, is quite common in Japanese as exemplified in 11. Are in 9B, which can be deleted, is a case of Situational Topic, referring to the state or environment (including the preceding context) under which the utterance is made.

(10) a. Come tomorrow if (it is) possible. (Curme 1977: 329)

b. This is the Elephant's Child having his nose pulled by the Crocodile. (A caption for a picture) ${ }^{3}$

(11) a. Kore-wa miti-o matigae-ta. this-top way-acc mistake-past

(Lit.) 'Speaking of this, (I) lost my way.'

b. Are-wa zettaini Amerika-ga warui. (Mikami 1960: 84) that-top absolutely -nom bad

(Lit.) 'Speaking of that, America is absolutely bad.'

c. A: John-ga dokokani saifu-o otosi-ta. -nom somewhere purse-acc lose-past 'John lost (his) purse somewhere.'

B: Sore-wa koto da. that-top fact be

(Lit.) 'Speaking of that, (it is) a serious fact.'

An important distinguishing property of Situational Topic constructions is that they cannot have the overt external argument in cases like 11; Are-wa, when it is a Situational Topic, does not have an alternate with a $\mathrm{ga}$-phrase, as shown in $12 \mathrm{~b}-\mathrm{c}$.

(12) a. Are wa, nezumi da. that-top mouse be

(Lit.) 'That is a mouse.'

b. \#John-ga [are ga nezumi da] to it-ta. -nom that-nom mouse be COMP say-past 'John said that that is a mouse.'

c. \#Are ${ }_{i}$-wa $\left[\mathrm{so}_{i}\right.$-no namae-ga nezumi da] that-top it-gen name-nom mouse be

(Lit.) 'Speaking of that, its name is mouse.' (\# means the sentences are o.k. in the sense of definite

${ }^{3}$ I am indebted to Shigeki Seki (p.c.) for this example. 
pronouns, but not in terms of Situational Topic.)

I would like to differentiate Situational Topic, Topic $\mathrm{c}_{\mathrm{s}}$, from the usual topic, Topic ${ }_{\mathrm{U}}$, such as the wa-phrases in 4 and 5. Although wa-phrases more or less depend on context, it is reasonable to consider Topic $\mathrm{S}_{\mathrm{S}}$ is more heavily dependent on the discourse than $\mathrm{Topic}_{\mathrm{U}}$, and also reflecting the speaker's modality at the time of utterance (cf. Nakau 1979). In this sense, Topic $\mathrm{S}_{\mathrm{S}}$ can be called Topic of Modality (Topic $\mathrm{M}_{\mathrm{M}}$ ). I propose that the different properties of the two types of Topic can be characterized in the D-structure representation; Top $_{U}$, following Kuno 1973, is adjoined to $\mathrm{S}$ (IP) and Top (or $^{\mathrm{T}} \mathrm{Top}_{\mathrm{M}}$ ) to $\mathrm{S}^{\prime}(\mathrm{CP})$. Both Topics can be zero in the sense of Huang 1984.

Thus, based on the argument so far made, Topic ${ }_{U}$ and Topic $\mathrm{S}_{\mathrm{S}}$ can be schematically represented as in 13 (A detailed representation of $\mathrm{Top}_{\mathrm{S}}$ will be deferred to the later sections). $14 \mathrm{~B}$ is an example in which both types of Topic co-occur:

(13) $\left[s^{\prime}\left[\operatorname{ToP}_{S} \ldots\right]\right.$ [s [TOPU $\left.\ldots\right]$ [s ...]]]

(14) A: Donna sakana-ga oisii desu ka? which fish-nom tasty polite $Q$ 'Which fish is tasty?'

B: Sore-wa (motiron) [Sakana-wa [tai-ga oisii]] that-top (of course) fish-top red snapper-nom tasty

(Lit.) 'Speaking of that, (of course) red snapper is tasty.'

As an answer to the question 9A above, 9C, besides 9B, is an appropriate answer, where epistemic modal type expressions like no da or yoo da and Situational Topic co-occur:

(9) C: Are-wa nezumi-ga gokiburi-o oikaketeiru no/yoo mouse-nom cockroach-acc chaising $\mathrm{N}$

da.

be

'It is (seems) a mouse is chasing a cockroach.'

I would like to claim in the following sections that sentences like 1 are of the Situational Topic construction, by specifically adopting the Incorporation analysis proposed by Baker 1985, 1988.

2. INCORPORATION ANALYSIS OF DA-CONSTRUCTIONS. Incorporation is a process in which one semantically independent word moves out of its phrase in D-structure to combine with another word. It is assumed that it is fundamentally the same process as the generalized transformation 'Move $\alpha$ ', though the moved element is a zero-level category instead of 
the maximal projection.

Thus in conjunction with the Empty Category Principle (ECP), the following Head Movement Constraint (HMC) should be observed (cf. Travis 1984: 131, Baker 1985: 66, Chomsky 1986b: 71):

(15) An $X^{0}$ may only move into the $Y^{0}$ which properly governs it.

Let us assume that $d a$ can be categorized according to the properties of the category, with which $d a$ relates, as illustrated in 16 .

\begin{tabular}{|c|l|l|}
\hline$[\ldots \mathrm{XP}]$ & $d a$ & \multicolumn{1}{|c|}{ examples } \\
\hline $\mathrm{VP}$ & \multirow{2}{*}{ Infl } & cf. (36) and fn. 9 \\
\cline { 3 - 3 } $\mathrm{N}[$ +lexical $]$ & & {$\left[[\text { daitooryoo }]_{\mathrm{N}}\right]_{\mathrm{NP}} d a$} \\
\hline $\mathrm{N}[\text {-lexical }]^{4}$ & Verb & {$[\ldots n o]_{\mathrm{NP}} d a$} \\
\hline
\end{tabular}

The correlation between the head of NP and the category of $d a$ can be expressed in such a way that if the head $\mathrm{N}$ is strong, then the category of $d a$ is weak, and vice versa.

Let us examine sentences like 17, in which soo, yoo, hazu, koto, and no are used with $d a$. Sentences like 17 are used to express the speaker's personal assessment of the content of the complement clause at the time of utterance.

(17) a. Mamonaku basu-ga kuru yoo da. soon bus -nom come seem be 'It seems that a bus will come soon.'

b. Chomusukii-ga Nihon-ni kuru soo da. Chomsky-nom Japan-to come said be 'It is said that Chomsky will come to Japan.'

c. Taroo-ga kyoo koko-ni kuru hazu da. Taro-nom today here to come be expected be 'It is expected that Taro will come here today.'

d. (Kimi-ga) Yattemiru koto da. you-nom have a try fact be

(Lit.) 'It should be that you have a try.'

e. Nanika kanasii koto-ga atta no da. something sad thing-nom happened $\mathrm{N}$ be

4 The feature [ \pm lexical] here is intended to differentiate the head $\mathrm{N}$ in terms of the semantic content that it has. Soo, yoo, no, koto, and the like, in the relevant constructions, have no independent meaning. 
(Lit.) 'It is that something sad happened.'

As for the analysis of sentences like 17, there are two possibilities: If we assume with Nakau 1973 that $d a$ is under Infl, as the Present Tense marker, we will have the following rough representation 18a (Soo is considered to be a nominal predicate.):

(18) a. [IP $_{\mathrm{NP}_{\mathrm{NP}}}$ e] $\left[_{\mathrm{I}^{\prime}}\right.$ [VP $_{\mathrm{VP}}$ Chomusukii-ga Nihon-ni kuru]

(=17b) [v soo]] [I da]]]

'It is said that Chomsky will come to Japan.'

$\mathrm{V}($ soo $)$ moves to I to form $\mathrm{V}_{\mathrm{I}}$, since $d a$ as an affix needs a bearer (Stray Affix Filter, Baker 1985, 1988), yielding the rough representation $18 \mathrm{~b}$ (See fn. 14 for the (im-)possibility of complement verb raising in sentences like 17 and 19 below):

(18) b. $\left[_{I P}\left[{ }_{N P}\right.\right.$ e] $I_{I^{\prime}}\left[{ }_{V P}\left[{ }_{C P}\right.\right.$ Chomskii-ga Nihon-ni kuru] $\left.\left[_{v} t_{i}\right]\right]\left[_{V I}\right.$ soo $_{\mathrm{i}}$-da]]]

Here the VP is L-marked by $\mathrm{V}_{\mathrm{I}}$, and hence is not a barrier for V-raising. (Chomsky 1986b: 69) Also following Koopman 1984, the non-existence of a modal in Infl allows a main verb to move into Infl by means of V-raising. In this paper, I assume that the idea of treating $d a$ as an affix (Tense marker) is relevant not in a sentence like 1 , but in a sentence like 19 , which I believe is a similar but different construction from 17b (See 16, and 36 below):

(19) Chomusukii-ga Nihon-ni ki soo da. -nom Nihon-to come likely-be

'Chomsky is likely to come to Japan.'

Yoo and soo can be analyzed as (raising) predicates, as in Nakau 1973, but as for no, koto, hazu, and the like, I intuitively feel that these are nouns, but not predicates-although, theoretically, my present position is not strong enough to argue against Nakau's analysis of all these elements as predicates. However, since this paper has no-da, koto-da, and hazu$d a$, as well as yoo-da and soo-da in its general perspective, we will take the second alternative: the Noun Incorporation analysis.

In this case, soo, yoo, hazu, no, and koto are classified as nouns, ${ }^{5}$ and are incorporated to the verb $d a$, yielding the structural change as in 20. It should be noted that I am assuming here that the verb $d a$ is an unaccusative verb with a subcategorization frame like 21 (See Stowell 1978, Burzio 1986, Perlmutter 1978, among others).

5 These words have been called Keisiki Meisi (Formal Noun) in traditional Japanese grammar. 
(20)

a.

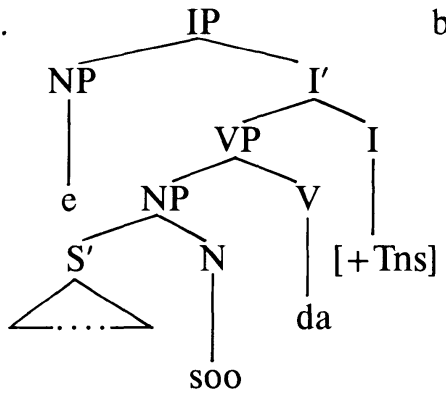

b.

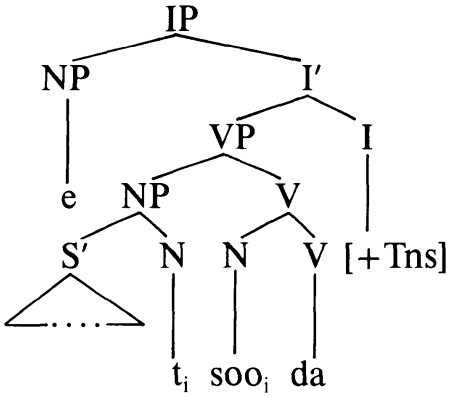

(21) $d a, \mathrm{~V}:[-\mathrm{NP}]$ (the order is irrelevant)

external theta role: $\phi$

This analysis is along the same line as Hyams 1986 in arguing that avere and essere (have and be in English), though somewhat 'auxiliary-like' elements in their behavior, are not generated under Infl, but are verbs which are subcategorized for a sentential complement. The difference lies in the fact that $d a$ is subcategorized for an NP in this case. ${ }^{6}$

Under the mechanism of the unaccusative hypothesis, the internal argument of an unaccusative verb $d a$ is supposed to get Case somehow. However, Noun Incorporation has important effects with regard to the Case Filter in the following manner:

(22) Incorporated noun and the NP that it heads need not be as-

${ }^{6}$ Though tumorida 'intend' seems to be a combination of tumori+da, it is a different verb in that the meaning of tumorida is reflecting the subject's intention, hence the subject NP is $\theta$-marked, unlike soo-da, yoo-da, no-da, hazu-da, and the like. This explains the contrast between (i) and (ii), and between (iii) and (vi), respectively (cf. Nakau 1973: Chapter V):

( i ) Taroo-ga Hanako-o paatii-ni sasou tumorida. party-to invite intend

'Taro intends to invite Hanako to the party.'

(ii) Hanako-ga Taroo-ni paatii-ni sasowareru tumorida.

'Hanako intended to be invited by Taro to the party.'

(iii) Taroo-ga Hanako-o paatii-ni sasou yoo da. party-to invite intend

'It seems Taro invites Hanako to the party.'

(vi) Hanako-ga Taroo-ni paatii-ni sasowareru yoo da.

'It seems Hanako is invited by Taro to the party.'

Whose intention is involved with the invitation to the party does not matter in (iii) and (vi), while it matters in (i) and (ii).

In the present framework, this fact can be explained by assuming that tumorida has base-generated verbal status, not being derived through Incorporation. This observation is due to Hideo Ohashi (p.c.). 
signed Case. (Baker 1985, 1988) ${ }^{7}$

Thus, the sentence is grammatical without Case in sentences like 17. The chain formation between the incorporated noun and its trace, and hence the internal argument NP saves the Visibility Condition into which the Case Filter is reduced. (Chomsky 1986a)

The structural change of 20 establishes the theta-indexing relation between the incorporated noun soo, and hence, the complex verb soo-da and the complement clause by means of the Government Transparency Corollary (GTC) 23. Thus, at LF, where Predication relationships and the scopal relations of quantifiers and operators are represented, the complement clause of soo actually stands in a verb-complement relation with the complex verb, as shown in 24:

(23) The Government Transparency Corollary (GTC)

A lexical category which has an item incorporated into it governs everything which the incorporated item governed in its original structural position.

(Baker 1985: 79)

(24) e [vp $\left.\left[\mathrm{NP}_{\mathrm{S}^{\prime}} \ldots\right] \mathrm{t}_{\mathrm{i}}\right]\left[\mathrm{v}_{1}\right.$ soo $_{\mathrm{i}}$-da] $]$

(Arabic numeral subscript stands for theta-coindexing.)

In the next section, some theoretical implications that the present analysis induces will be discussed.

3. The Null Subject Parameter in Japanese: Some TheoretiCAL IMPLICATIONS. Adoption of Baker's Incorporation analysis as in 20 does not exclude the possibility that the complex $\mathrm{V}$ moves to I, yielding $\mathrm{V}_{\mathrm{I}}$. Here as usual, the VP, which is L-marked by $\mathrm{V}_{\mathrm{I}}$, is not a barrier between the two elements, as illustrated in 25:

(25)

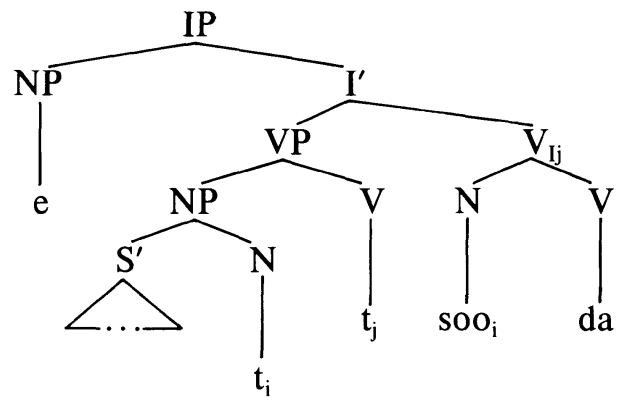

${ }^{7}$ Note that 32 is not to say that such a nominal cannot be assigned Case. See Baker 1988: $124 \mathrm{ff}$. for Case variation in NI constructions. 
If we assume these predicates are of a pronoun-like nature, the amalgamated $V_{I}$ is also pronominal (that is, pronominal Infl derivatively). This assumption makes the correct prediction about the NS status of each of the sentences in 17 without contradicting the well-known proposals on the Null Subject Parameter (Rizzi 1982 attributes the missing subject property to the possibility that Infl can be pronominal). The null subject is Case-marked (nominative Case) by Infl (actually the amalgamated $\mathrm{V}_{\mathrm{I}}$ ), conforming with the formal requirement of pro licensing. (Rizzi 1986: 524) See Takezawa 1987 for nominative Case assignment by Infl. A brief discussion of nominative Case assignment will be made below. ${ }^{8}$

As for recovery of the content of pro, the null subject is not $\theta$-marked and has no co-indexed features, thus acting as an expletive element like English it and there. (Since Japanese does not have overt expletives, zero expletives, I assume, function in ways equivalent to English it and there. $)^{9}$

Baker notes the parallelism between clitic constructions and Incorporation structures. In configuration 26, following Borer 1983, it is possible to say that the incorporated (pro-)noun like soo, no, yoo, and others have a clitic-like nature. (Borer 1983: 35-6, Baker 1988: 55, 449.)

8 Takezawa 1987 argues that Infl [+ Tense] governs and Case-assigns the subject of tensed clauses in Japanese. He also states that languages differ in selecting either Agr or (tensed) Infl as nominative Case assignment. He claims that Japanese is one of those languages in which the presence of Tense, rather than Agr, is responsible for nominative assignment.

9 If we assume the outside verbal representation (ii) ( $d a$ is categorized as Infl here. See 16.) for sentence (i), spoken by a TV reporter, (i) can be characterized as the presentational sentence, one usage of a There-sentence like (iii) (I assume (ii) is base-generated here.). It can be assumed that (e, Seko) is a so-called expletive-argument pair. Thus Sentence (iv) is also available in the same situation:

(i) (Kotira-wa) [Kaichooni hasitteiru] Seko-senshu desu. (this-top) in good condition running runner Seko polite-be

(Lit.) '(As for this) There/it is Seko running in good condition.'

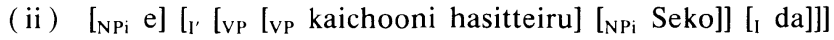

(iii) There walked into the room an old man.

(iv) (Kotira-wa) Seko-senshu-ga kaichooni hasitteimasu.

(Lit.) '(As for this) Seko is running in good condition.'

Presentational interpretation involves the introduction into discourse of a new element which is presented as the focus of the sentence (Safir 1985 and references cited there). Sentence (i) can be used in this manner. See Tsubomoto in preparation for a pertinent detail, where several other types of Japanese inversion constructions are discussed. 
(26)

a.

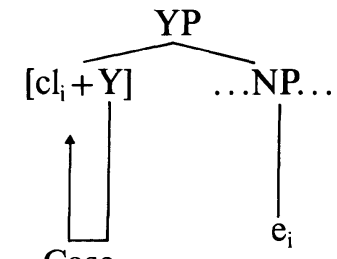

Case

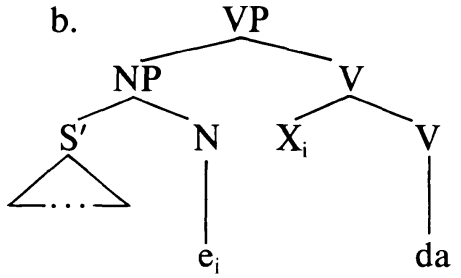

absorption

CLITICIZATION

INCORPORATION

In parallel with the system of 26a, where the clitic absorbs the Case features of $Y$, the incorporated noun $X$ absorbs the case features of the head, da. This manner of explanation also correctly comes to the rescue of the NP's Case Filter violation in 26b.

Since we assume incorporated items like soo, koto, no, yoo, and the like are pronouns, they should observe Binding Condition (B), namely that pronominals are free in the governing category. Pronominals can be either bound (outside the GC) or arbitrary. My contention here is that those pronominal clitic-like elements have a binder, without violating the Binding Theory. The only possible candidate as a binder is Topic (either Zero-Top or overt Topic), as roughly illustrated in $(27=17 \mathrm{e})$ :

(27) $\left[_{\mathrm{CP}}\left[_{\mathrm{TOP}}\right.\right.$ e] $\left[_{\mathrm{IP}}[\mathrm{e}] \mathrm{I}_{\mathrm{I}^{\prime}}\left[_{\mathrm{VP}}\left[_{\mathrm{NP}}[\mathrm{CP} \ldots\right.\right.\right.$ kanasii koto-ga

atta] $\mathrm{t}] \mathrm{t}]\left[\mathrm{v}_{\mathrm{I}}\right.$ no
happened
binding
sad thing-nom

Here, IP is a Governing category in which pronominal no is free observing the binding condition. Pronouns can be interpreted as either definite or arbitrary, which is identified from the situational information (including the preceding context) of the discourse, i.e. Situational Topic (with modality nature). ${ }^{10}$

10 Thus, the intended interpretation of a sentence like (ia) can be abstractly represented as in (ib):

(i ) a. [Ame-ga huru] yoo-da. rain-nom fall seem-be 'It seems to rain.'

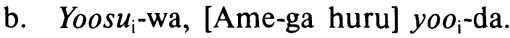
atomosphere-top Pro-N

(Lit.) 'As for the atomosphere, rain seems to fall.' 
In certain cases, some of those instances can be used as generic (arbitrary) expressions, meaning that the speaker judges that it is generally the case, as shown in 28.

(28) Gakusei-wa benkyoo suru mono da. students-top study do

(Lit.) 'It is generally the case that students study.'

Alternatively, the relation between Topic $\mathrm{s}_{\mathrm{s}}$ and the amalgamated verb, epistemic modals in nature, can be captured by the Spec-head agreement (Chomsky 1986b: 24) to the effect that the amalgamated verb $V_{I}$ 'epistemic modal' in its behavior, further moves to the COMP position, ${ }^{11}$ which in turn agrees with Topic $\mathrm{s}_{\mathrm{S}}$, as illustrated in 29.

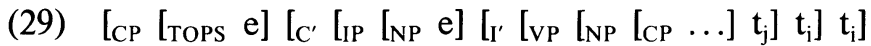

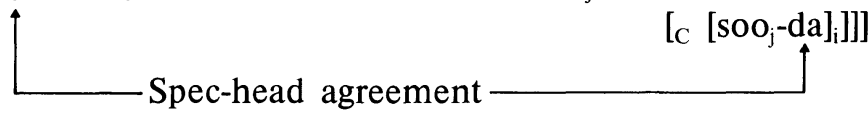

The paradigm 30 shows that Topic s $_{\mathrm{s}}$ ilikely to co-occur with certain epistemic modals (amalgamated verbs in the present framework).

(30) a. A: Hanako-ga naite iru.

-nom crying

'Hanako is crying.'

B: Sore-wa, tabun nanika kanasii koto-ga

that-top probably something sad thing-nom

atta $*$ (no da).

happened

(Lit.) 'Speaking of that, it is probably that something sad happened.'

b. A: Rainen Amerika-ni iki-masu.

next year America-to go-polite

'Next year, I will go to America.'

B: Sore-wa, sikkari eigo-o benkyoo suru *(koto da). hard English-acc study do

(Lit.) 'Speaking of that, it is necessary that you study English hard.'

The Topical component may not appear overtly, but my contention is that sentences like 17 without the overt Topic, following Huang's Zero-

11 Ohashi 1987 argues that epistemic-type modals are clausal operators, which move to COMP by LF operator movement. I assume here COMP moves at S-structure. 
Topic parameter, have a respective (Zero) Top which binds the pronominal element in the amalgamated predicates (or modal auxiliaries), as in the case of the overt Topic like 30. Usually, a Zero-Topic can be designated in the context where the sentences are uttered. It can also be stipulated that Japanese can be characterized as a Topic-agreement language to the effect that Topic $_{S}$, which can also be characterized as Topic of Modality (somehow conjunctive), is concurrent with epistemic modallike elements in sentences like 17, though there is no 'strong agreement' in Japanese (cf. Kuroda 1986, Fukui 1986).

Though the grammaticality difference sometimes does not clearly appear, these epistemic modal-like elements often cooccur with what can be termed EPISTEMIC ADVERBS as 31 shows:

(31) a. Dooyara ame-ga huru??(yoo da). apparently rain-nom fall seem

'It is likely that it will rain.'

b. Kimi-wa zettai New York ni iku??(koto da). you-top absolutely -to go fact

(Lit.) 'Absolutely it should be that you go to N.Y.'

c. Tumari Nihon-no seiji-ga natte nai??(no da). in short Japanese-gen politics-nom poor

(Lit.) 'In short, it is that Japanese politics is poor.'

d. Nandaka Chomusukii-ga Nihon-ni kuru??(soo da). somehow -nom Japan-to come

(Lit.) 'Somehow it is said that Ch. will come to Japan.'

e. Motiron John-ga daitooryoo-ni naru(?)(hazu da). ${ }^{12}$ of course -nom President-dat become 'Of course, John should be the President.'

This fact can be captured by assuming that these adverbs function as operators and move to the Spec $(\mathrm{CP})$ position at $\mathrm{LF}$, yielding the same scopal relation with the epistemic element. The existence of these two types of elements in Spec (CP) needs a certain elaboration on the Topic node, the former Topic $_{S}$, in 13, which I assumed is the Specifier position of CP. If those adverbs move to Spec (CP), what relations do a Situational Topic and the adverbs have? Liu 1986: 150 extends May 1986's proposal on the projection set to D-structure and assume that $\left\{\mathrm{CP}_{1}\right.$ and $\left.\mathrm{CP}_{2}\right\}$

12 The sentence without hazu da, which is used with assertive sense, sounds o.k., because the assertive meaning can also be expressed with a simple verbal form. 
constitutes a projection set. Representation 32 roughly illustrates the two types of Spec (CP). ${ }^{13}$ The CP node is doubly represented in 32 . I claim Spec $\left(\mathrm{CP}_{1}\right)$ is where Situational Topic (Topic $\left.\mathrm{S}_{\mathrm{S}}\right)$ resides and that Spec $\left(\mathrm{CP}_{2}\right)$ is the landing site for epistemic adverbs $\left(\operatorname{adv}_{\mathrm{E}}\right)$, which are assumed to move at LF (the general transformation Move $\alpha$ ). Thus, the amalgamated element, epistemic-modal in its behavior, agrees with Spec (CP) in terms of the feature [+ Modality].

(32) $\left[_{\mathrm{CP} 1} \operatorname{Top}_{\mathrm{S}}\left[_{\mathrm{CP} 2}\left[\mathrm{adv}_{\mathrm{Ej}}\right]\left[_{\mathrm{C}^{\prime}}\right.\right.\right.$ IIP $_{\mathrm{IP}} \mathrm{Top}_{\mathrm{U}}\left[_{\mathrm{IP}}\right.$ e $\left[_{\mathrm{I}^{\prime}}\left[_{\mathrm{VP}}\left[_{\mathrm{NP}}[\mathrm{CP} \ldots\right.\right.\right.$ $\left.\left.\left.\left.\left.\left.\left.\left.\ldots e_{j} \ldots\right] t_{k}\right] t_{i}\right] t_{i}\right]\right]\left[c[\{\text { soo/yoo/koto/no/...k }\} \text { da }]_{i}\right]\right]\right]\right]$

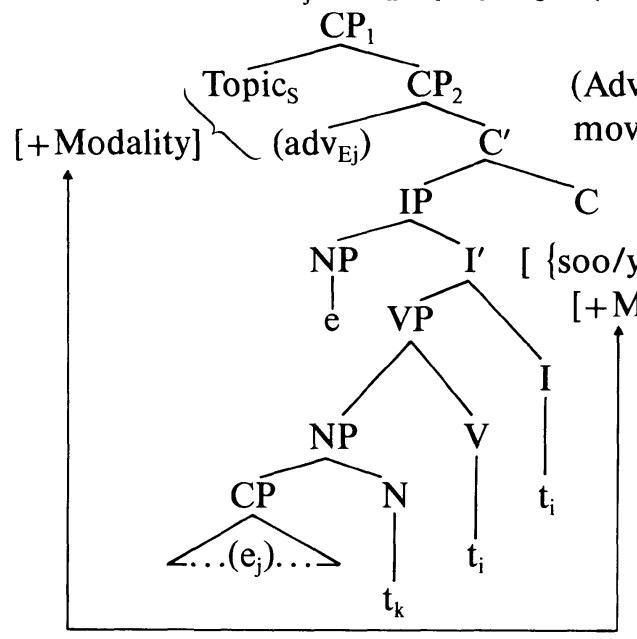

Note that the CP, in which the $\operatorname{adv}_{\mathrm{E}}$ may overtly appear, is not a barrier for Adverb-movement because the clause stands in a verb-complement relation with the help of the GTC (cf. 24). VP is also not a barrier, because VP is L-marked by (amalgamated) $\mathrm{V}_{\mathrm{I}}$. (cf. 25)

The second position, Spec $\left(\mathrm{CP}_{2}\right)$, can be validated by comparing with WH-movement, for which Spec $\left(\mathrm{CP}_{2}\right)$ is also the landing site (Chomsky 1986b). Consider the examples in 33:

(33) a. Motiron/kitto John-ga Mary-ni hon-o yatta no da. of course/surely -nom -dat book-acc give-past 'Of course/Surely, John gave Mary a book.'

13 Alternatively, we can assume with Chomsky 1977 that there is a further projection of $\mathrm{S}^{\prime}(\mathrm{CP})$ to $\mathrm{S}^{\prime \prime}$, i.e. $\mathrm{CP}^{\prime}=$ TOP CP. However, this expansion of the maximal projection is intricately connected with the problem of the maximal projection. I will not go into this problem further here. 
b. John-ga Mary-ni nani-o yatta no da?

what-acc

'What did John give Mary?'

c. *Motiron/Kitto John-ga Mary-ni nani-o yatta no da?

Since the same specifier position cannot be filled doubly, example 33c is out. In contrast with 33 , the sentences in 34 , where quantifiers, nanika 'something' or dareka 'someone' are used in stead of WH-words, are o.k. This grammaticality difference can be explained by assuming with May 1985 that the rule QR adjoins the quantifier to IP or VP, and hence no conflicts arise between the quantifiers and the epistemic adverbs.
a. Motiron/Kitto John-ga Mary-ni nanika-o of course/surely -nom -dat something-acc yatta no da.
give-past
'Of course/Surely, John gave Mary something.'
b. Motiron/Kitto John-ga dareka-ni hon-o yatta no da. someone-dat
'Of course/Surely, John gave someone a book.'

We will not go into this intriguing problem further here. Note $\operatorname{Adv}_{\mathrm{E}}$, which I assume is $[-\mathrm{Q}(k a)]$, contradicts with $\mathrm{Q}(k a)$ in $\mathrm{C}$ in general.

Finally, let us consider a similar, but different construction 19 , which I repeat as $35 \mathrm{a}$ for convenience.

(35) a. Chomusukii-ga Nihon-ni ki soo da. -nom Japan-to come seems

'Chomsky seems to come to Japan.'

b. Chomusukii-ga Nihon-ni kuru soo da.

'It is said that Chomsky will come to Japan.'

I assign to $35 \mathrm{a}$ the D-structure representation 36 . Note that in this case $d a$ is not a $\theta$-assigning verb, but generated under the Infl node as a Tense marker (cf. 16).

(36) $\left[\left[_{N P}\right.\right.$ e] [I' [VP [IP Chomusukii Nihon-ni ki] [v soo]] [I da]]]] [-Case $]$

I assume the complement IP of the verb soo is nonfinite. If nominative Case, following Takezawa 1987, can be assigned by (Tensed) Infl, the internal subject Chomusukii 'Chomsky' cannot get Case because of the nonfiniteness of IP. It cannot get Case outside IP, in an ECM manner, by soo, a raising verb. Thus, in order to avoid the Case Filter violation, as in the case of an English raising construction 37, the subject NP must move 
to where it can get Case. In 38, I assume that $k i$ 'come' raises to combine with soo to form ki-soo, to which in turn V-Incorporation is applied, and the amalgamated $\mathrm{V}_{\mathrm{I}}$ assigns nominative Case to the raised NP and no Case Filter violation results.

(37) $\mathrm{John}_{\mathrm{i}}\left[\mathrm{seem}_{\mathrm{j}}-\mathrm{I}\right]\left[\mathrm{lvP}_{\mathrm{vP}} \mathrm{t}_{\mathrm{j}}\left[_{\mathrm{IP}} \mathrm{t}_{\mathrm{i}}\right.\right.$ to come]

(38) a. $\left[\left[_{N P}\right.\right.$ Chomusukii $\left.i_{i}-g a\right] I_{I^{\prime}}\left[{ }_{V P}\left[{ }_{I P} t_{i}\right.\right.$ [Nihon-ni $\left.\left.t_{k}\right]\right]$

[v $\mathrm{ki}_{\mathrm{k}}$-soo]] [ [ da]]]

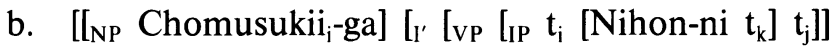

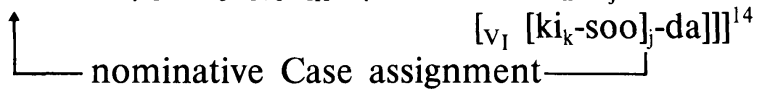

Sentence $35 \mathrm{a}$, as well as $35 \mathrm{~b}$, describes the whole atmosphere. This intuition can be attributed to the above same assumption that this amalgamated $\mathrm{V}_{\mathrm{I}}$, with epistemic properties of soo-da, moves to COMP, yielding Spec-head agreement with 'Situational Topic'.

4. Conclusion. The purpose of this paper has been to consider the non-overt NP in the canonical subject position and the Topic node of sentences like 1 by assuming that the characteristics which those sentences have can be attributed to the nature and properties of $d a$, in connection with what I call the SitUATIONAL Topic construction. With the

14 Thus ki-soo behaves like complex predicates as a result of complement verb raising, while kuru soo does not because of the lack of this operation. Nakau 1973: $289 \mathrm{ff}$., clearly discusses this contrast by means of phonological evidence. The sentences in (i) differ in accentual pattern in spite of the identical phonological strings. This contrast can be attributed to the property of nige-ta-soo 'looks like (he) wishes to escape' as the complex predicate, while nige-ta soo 'be said to have escaped' is not a complex predicate since nige-ta 'escaped' and soo 'be said to' each function in accent placement, as all simplex predicates do.

(i ) a. Doroboo-ga $\{$ NIge-ta SOO da/*nige ta SOO da $\}$.

thief-nom excape-past is said

'It is said that the thief escaped.'

b. Doroboo-ga $\{*$ NIge ta SOO da/nige ta SOO da $\}$. escape wish look like look like

'The thief looks like (he) wishes to escape.' (cf. Nakau 1973: 289)

Sentence (ii), which is a sentence of type $35 \mathrm{a}$, behaves exactly like simplex predicates with respect to accentual pattern:

(ii) Doroboo-ga $\{*$ NIge SOO da/nige SOO da $\}$.

'The thief looks like (he is) going to escape.' (Nakau ibid.)

The possibility of complement verb raising in Japanese vis-â-vis English may be attributed to the head-complement parameter (head-last in Japanese), yielding the adjacent relation between the complement verb $k i$ and the matrix verb soo. 
help of Incorporation theory proposed by Baker 1985, 1988, the discussion started with two alternatives, the unaccusative analysis and the Affix (Tense marker) analysis with respect to $d a$. Based on either analysis, $d a$ cannot be stranded. It must combine with some element, yielding a synthetic form.

In Japanese, there are sentences in which Topic $\mathrm{s}_{\mathrm{s}}$, either overt or empty, co-occurs with epistemic modals (some are discussed as amalgamated verbs in this paper). This fact can be explained by assuming either that reflecting the Zero-Topic parameter proposed by Huang 1984, the incorporated item (pronominal clitic) is bound by the discourse-defined Topic (cf. fn. 10) or that epistemic modal-like verbs move to COMP, and are

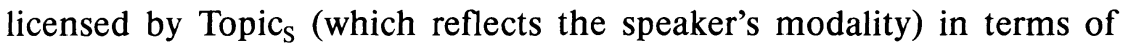
Spec-head agreement. Although there is no 'strong agreement' in Japanese (in the sense of, for instance, Kuroda 1986, Fukui 1986 in particular), it can be said that Japanese is a Topic (of Modality)-agreement language, as roughly illustrated in 39 below:

(39)

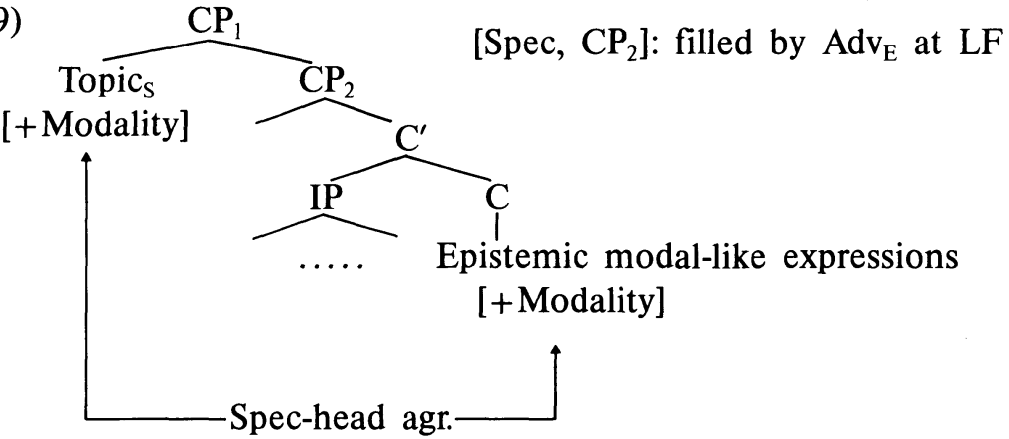

\section{REFERENCES}

BAKER, MARK. 1985. Incorporation: A theory of grammatical function changing. MIT dissertation.

1988. Incorporation. Chicago: University of Chicago Press.

Borer, Hagit. 1984. Parametric syntax. Dordrecht: Foris.

Burzio, Luiggi. 1986. Italian syntax. Dodrecht: Reidel Publishing Company.

Сномsку, Noam. 1977. On wh-movement. Formal syntax, ed. by Peter Culicover, Thomas Wasaw, and Adrian Akmajian, 71-132. New York: Academic Press.

- . 1981. Lectures on government and binding. Dordrecht: Foris.

- . 1982. Some concepts and consequences of the theory of government and binding. Cambridge, MA: MIT Press. 
—. 1986a. Knowledge of language: Its nature, origin, and use. New York: Praeger.

-. 1986b. Barriers. Cambridge, MA: MIT Press.

Curme, George. 1977. Grammar of the English language. vol. II. Essex, CT.: Verbatim.

FUKUI, NAOKI. 1986. A theory of category projection and its application. MIT dissertation.

HuANG, C.-T. JAmEs. 1984. On the distribution and reference of empty pronouns. LI $15.53-74$.

HoJI, HAJIME. 1985. Logical form constraints and configurational structures in Japanese. Univ. of Washington dissertation.

Hyams, Nina. 1986. Language acquisition and the theory of parameters. Dordrecht: Reidel Publishing Company.

Koopman, Hilda. 1984. The syntax of verbs. Dordrecht: Foris.

Kuno, Susumu. 1973. The structure of the Japanese language. Cambridge, MA: MIT Press.

Kuroda, Shige-Yuki. 1965. Generative grammatical studies in the Japanese language. MIT dissertation.

- 1987. Movement of noun phrases in Japanese. Issues in Japanese linguistics, ed. by Imai Takashi and Mamoru Saito, 229-71. Dordrecht: Foris.

- 1986. Whether we agree or not: A comparative syntax of English and Japanese. ms. UCSD.

LIU, FENG-HSI. 1986. On topic-traces in Chinese. WCCFL 5.142-53.

May, Robert. 1985. Logical form. Cambridge, MA: MIT Press.

McClosky, James, and Hale Kenneth. 1984. On the syntax of person-number inflection in modern Irish. NLLT 1.487-533.

Mikami, AKIRa. 1960. Zoo-wa hana-ga nagai. Tokyo: Kuroshio.

NaKaU, Minoru. 1973. Sentential complementation in Japanese. Tokyo: Kaitakusha.

- 1979. Modariti to meidai. Eigo to Nihongo to. 223-50. Tokyo: Kuroshio.

OHASHI, Hideo. 1987. Some interactions of modal auxiliaries and negation in Japanese: A case for the theory of binding at LF. ms. Chukyo University.

Perlmutter, David M. 1972. Evidence for shadow pronouns in French relativization, ed. by Peranteau Paul et al. The Chicago which hunt, CLS 73-105.

- 1978. Impersonal passives and the unaccusative hypothesis. BLS 4.157-89.

Rizzi, Luiggi. 1982. Issues in Italian syntax. Dordrecht: Foris.

- 1986. Null objects in Italian and the theory of pro. LI 17.501-57.

Rothstein, Susan. 1987. Three forms of English be. MIT working papers in Linguistics $9.225-38$.

SAdLeR, Louisa. 1988. Welsh syntax. London: Croom Helm.

SAFIR, KenNeth. 1985. Syntactic chains. London: CUP.

SAITO, Mamoru. 1985. Some asymmetries in Japanese and their theoretical implications. MIT dissertation.

Stowell, Tim. 1978. What was there before there was there. CLS 14.458-71.

StumP, Gregory. 1984. Agreement vs. incorporation in Breton. NLLT 2.289-348.

TAKEZAWA, KoICHI. 1987. A configurational approach to case-marking in Japanese. 
University of Washington dissertation.

Travis, Lisa. 1984. Parameters and effects of word order variation. MIT dissertation.

Tsuвomoto, Atsuro. in prep. Inversion constructions in Japanese.

Whitman, John. 1982 (=1987). Configurationality parameters. Issues in Japanese linguistics, ed. by Takashi Imai and Mamoru Saito, 351-74. Dordrecht: Foris. 